\title{
Analysis of an unusual hetero-halogen bonded trimer using charge density analysis: A case of concerted type I Br... Br and type II Br...Cl interactions
}

\author{
MYSORE S PAVAN and TAYUR N GURU ROW* (D \\ Solid State and Structural Chemistry Unit, Indian Institute of Science, Bangalore 560 012, India \\ e-mail: ssctng@sscu.iisc.ernet.in
}

MS received 2 May 2016; revised 18 June 2016; accepted 27 June 2016

\begin{abstract}
The crystal structure of 4-bromo-2-chlorobenzoic acid generates an unusual triangular motif consisting of a hitherto uncharacterized Type I Br $\cdots$ Br contact along with two Type II $\mathrm{Br} \cdots \mathrm{Cl}$ interactions as edges of the triangle. The nature of such bonding is analyzed based on both experimental and theoretical charge density followed by topological analysis.
\end{abstract}

Keywords. Halogen bond; electron density analysis; multipole refinement; intermolecular interaction.

\section{Introduction}

Hydrogen bonding is among the most widely studied noncovalent interactions in literature. ${ }^{1-3}$ Close on its heels comes the halogen bonding owing to its strength and directionality. ${ }^{4,5}$ In this context, the nature of halogen ... halogen contacts has been addressed by several researchers by various approaches which include variable temperature X-ray diffraction, ${ }^{6-9}$ statistical evaluation using Cambridge Structural Database ${ }^{8,10-13}$ and also by theoretical and experimental charge density. ${ }^{14-20}$ The halogen $\cdots$ halogen interactions observed in molecular crystals have been broadly classified as type I and type II contacts based on the geometry of the interacting $\mathrm{C}-\mathrm{X}$ groups (where $\mathrm{C}$ is the carbon atom and $\mathrm{X}$ is the halogen atom). The charge density studies published so far in literature have generally addressed the type II halogen ... halogen contacts as a "true halogen bond," while type I contacts are usually treated as a repulsive (dispersive) contact. Among the halogen contacts that have been investigated, $\mathrm{F} \cdots \mathrm{F}$ and $\mathrm{Cl} \cdots \mathrm{Cl}$ type I and type II contacts have received considerable attention (Scheme 1). ${ }^{16-18,21,22}$

But in case of bromine and iodine the investigations are limited to only type II contacts. ${ }^{19,20,23}$ Recently, there also have been experimental charge density studies on a unique arrangement of halogen atoms to form a triangular interaction motif, the so called $\mathrm{X}_{3}$ synthon, ${ }^{15,24}$ where the three interacting atoms are

*For correspondence

Celebrating 100 years of Lewis Chemical Bond nearly in type II geometry and forms a trimer. These studies on the $\mathrm{Cl}_{3}$ and $\mathrm{Br}_{3}$-synthons clearly established the extent of charge depletion and charge concentration region in the motif. ${ }^{15,19}$ The work also calculated the energy of the interaction based on the topological values at the critical point obtained from Bader's QTAIM approach. ${ }^{25}$

In this article, we investigate a triangular motif with type I $\mathrm{Br} \cdots \mathrm{Br}$, type II $\mathrm{Br} \cdots \mathrm{Cl}$ and type II $\mathrm{Cl} \cdots \mathrm{Br}$ contacts as its edges with two bromine and one chlorine atom at the vertices. The crystal structure of 4-bromo-2-chlorobenzoic acid (BRCL, Scheme 2) generates a triangular motif along with additional surrogate interactions, which augment the formation of the motif. The experimental and theoretical charge density distribution based on the aspherical multipolar modeling of electron density provides insights into the subtle features of the nature of such unusual interaction motifs. The study allows for the hitherto unexplored nature of an exotic type I Br. B Br contact in molecular crystals.

\section{Experimental}

\subsection{Preparation of single crystals}

The title compound was purchased from Sigma-Aldrich and was used for crystallisation without further purification. The single crystals of BRCL were grown from a saturated solution of methanol by slow evaporation and a suitable crystal for charge density analysis was selected using a polarising microscope. 


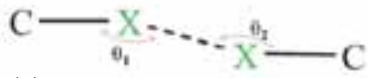

(a)

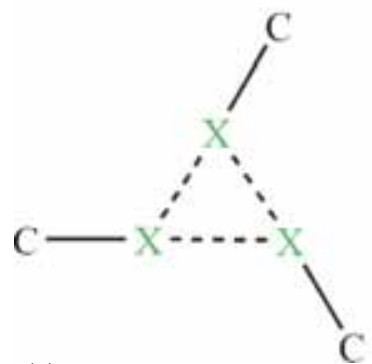

(c)

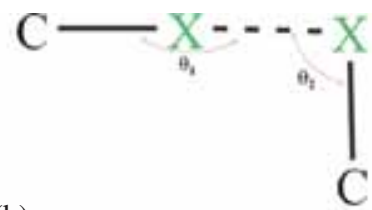

(b)

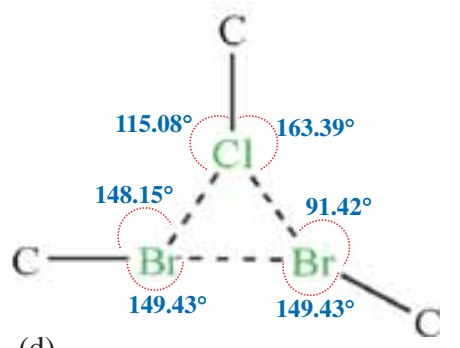

(d)

Scheme 1. Schematic representation of (a) Type I contacts, $\theta_{1}=\theta_{2}$; (b) Type II contacts, $\theta_{1} \approx 180^{\circ}, \theta_{2} \approx 90^{\circ}$; (c) $\mathrm{X}_{3}$ synthon, $\theta_{1} \approx 180^{\circ}, \theta_{2} \approx 120^{\circ}$; (d) Triangular motif in the present study.

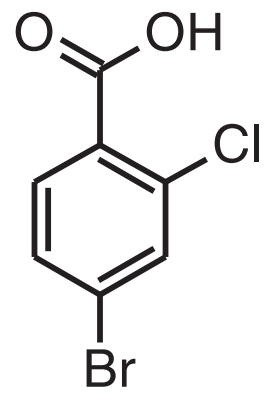

Scheme 2. 4-bromo-2-chlorobenzoic acid (BRCL).

\subsection{Data collection and structure refinement details}

The high resolution X-ray diffraction data on BRCL was collected on an Oxford Xcalibur (Mova) diffractometer equipped with an EOS CCD detector using MoK $\alpha$ radiation $(\lambda=0.71073 \AA)$. The data collections were done at $100 \mathrm{~K}$ using a liquid nitrogen stream from an Oxford Cobra non-liquid nitrogen gas-stream cooling device. The crystal to detector distance was fixed at $45 \mathrm{~mm}$ and the scan width $(\Delta \omega)$ was 1 per frame during the data collection. For the charge density data collection, the strategy was chosen in such a way to yield a high resolution X-ray data set $(\mathrm{d}=0.45 \AA)$ with high redundancy and completeness of $100 \%$. Cell refinement, data integration and reduction were carried out using the program CrysalisPro. Face indexing was done for the accurate numerical absorption correction. Sorting, scaling, and merging of the data sets were carried out using the program SORTAV. ${ }^{26}$ Both the crystal structures were solved by direct method using SHELXS2012 and refined based on the spherical-atom approximation using SHELXL2012 included in the WinGX suite..$^{27,28}$ Packing diagrams were made using Mercury 3.5. ${ }^{29}$

\subsection{Multipole Modeling}

The charge density modeling and multipolar aspherical atom refinements for BRCL were performed based on the Hansen and Coppens multipole formalism using XD2006. ${ }^{30-32}$ The function $\sum w\left[\left|F_{o}\right|-\left|F_{c}\right|\right]$ was minimized for all reflections with I $>2 \sigma$ (I). Weights (w) were taken as $1 / \sigma^{2}\left(\mathrm{~F}_{\mathrm{o}}^{2}\right)$ and convergence criterion of the refinement was set to a maximal shift/esd $<10^{-10}$. From the list of scattering factor wave functions available in the XD package, the basis functions and single- $\zeta$ values were taken from the databank-file of Su-CoppensMacchi. ${ }^{33,34}$ The scale factor was refined against the whole resolution range of diffraction data in the first refinement step. The scatter plot of the variation of $F_{\text {obs }}$ with $F_{\text {cal }}$ is indicative of the good quality of the data set after scaling (see Supplementary Information). The scale factor was refined against the whole resolution range of diffraction data in the first refinement step. The scatter plot of the variation of $\Sigma F_{\text {obs }}$ $/ \Sigma F_{\text {cal }}$ with resolution is indicative of the good quality of the data set after scaling (ESI). Positional and anisotropic displacement parameters of all the atoms were refined against the whole resolution of data. The multipolar populations were unconstrained during the refinements. Further scale, positional and anisotropic displacement parameters, $\mathrm{P}_{\mathrm{val}}, \mathrm{P}_{\mathrm{lm}}, \kappa$ and $\kappa \sim$ on all atoms were refined in a stepwise manner, until the 
convergence criterion was reached. Separate $\kappa$ and $\kappa^{\prime}$ parameters were used to define different atom types based on their chemical environments. The multipole expansion was extended to hexadecapoles in case of the bromine and chlorine atoms $(1=4)$ and were truncated at the octupole level for other non-hydrogen atoms $(1=3)$. For the $\mathrm{H}$ atoms, only monopole and bond directed dipole (D0) components were refined during the multipole refinements. In addition to these parameters the anharmonicity on bromine and chlorine atoms were treated by refining the Gram-Charlier cumulative of third order. An isotropic, type I extinction correction with a Lorentzian mosaic distribution was included in the refinement to improve the scaling of reflections and improve the residuals. ${ }^{35}$ The quantitative analysis of the electron density topology and related properties was performed using the XDPROP module of XD software suite. The relevant crystallographic and refinement details are listed in Table 1.

\subsection{Computational details}

Positional parameters obtained from the multipolar refinement have been used for the density functional theory calculations using the m-GGA functional M062X with TZVP basis set included in CRYSTAL14 package. ${ }^{36-38}$ The shrinking factors (IS1, IS2, and IS3) and the reciprocal lattice vectors were set to 4 (with $36 \mathrm{k}$-points in irreducible Brillouin zone). The bielectronic Coulomb and exchange series values for the truncation parameter were set as ITOL1-ITOL4 $=6$ and ITOL $5=14$, respectively for the calculations. The level shifter was set to 0.7 Hartree/cycle. An SCF convergence limit of the order of $10^{-7}$ Hartree was used. Upon convergence, the periodic electron densities as obtained from the wave function was subjected to the topological analysis by Bader's Quantum Theory of Atoms in Molecules (QTAIM) ${ }^{25}$ using TOPOND program which is directly interfaced with CRYSTAL14 code. 2D Laplacian maps for the interaction regions have been generated using the plotting utilities.

The interaction energy calculation between stacking dimers was accomplished using DFT methods in Gaussian09 software. ${ }^{39}$ The WB97XD, dispersion corrected functional with $6-311++(2 d, 2 p)$ as the basis set were used in the calculation ${ }^{40}$ BSSE corrections were incorporated alongside the calculations. ${ }^{41,42}$

\section{Results and Discussion}

\subsection{Crystal Structure analysis}

4-bromo-2-chlorbenzoic acid crystallizes in a monoclinic, $P 2_{1} / n$ space group with $Z=4$. The ORTEP of the asymmetric unit is shown in Figure 1a. The major hydrogen bonds which govern the packing include the carboxylic acid dimers $\mathrm{O}-\mathrm{H} \cdots \mathrm{O}$, followed by the $\mathrm{C}-\mathrm{H} \cdots \mathrm{O}$ infinite chains (Figure $1 \mathrm{~b}$ ). The $\mathrm{C}-\mathrm{H} \cdots \mathrm{O}$ hydrogen bonds do not form a sheet like arrangement, but rather pack in orthogonal directions to the acid dimers. The bromine atom in the structure is held together by an intermolecular type $\mathrm{I} \mathrm{Br} \cdots \mathrm{Br}$ contacts (Figure 1c). On careful examination of the type I $\mathrm{Br} \cdots \mathrm{Br}$ contact, it is observed that several additional interactions connecting the dimers, a weak $\mathrm{C}-\mathrm{H} \cdots \mathrm{Cl}$

Table 1. Crystallographic and structure refinement details.

\begin{tabular}{lccc}
\hline$C C D C$ No. & 1415427 & Reflns. collected & 64270 \\
Mol. formula & $\mathrm{C}_{7} \mathrm{H}_{4} \mathrm{BrClO}_{2}$ & Unique reflns. & 10883 \\
Formula weight & 235.46 & Completeness $(\%)$ & 99.9 \\
Crystal system & Monoclinic & Redundancy & 6 \\
Space group & $P 2_{1} / n$ & $\mathrm{R}_{\text {int }}$ & 0.058 \\
$\mathrm{a}(\AA)$ & $7.2708(1)$ & Spherical atom refinement \\
$\mathrm{b}(\AA)$ & $9.0590(1)$ & $\mathrm{R}_{1}(\mathrm{~F})$ & 0.031 \\
$\mathrm{c}(\AA)$ & $11.7182(2)$ & $\mathrm{wR}_{2}\left(\mathrm{~F}^{2}\right)$ & 0.054 \\
$\beta\left({ }^{\circ}\right)$ & $102.947(2)$ & $\mathrm{Goodness}^{\circ} \mathrm{of}-\mathrm{fit}$ & 0.96 \\
$\mathrm{~V}\left(\AA^{3}\right)$ & $752.21(2)$ & $\Delta \rho_{\text {min,max }}\left(\mathrm{e} \AA^{-3}\right)$ & $-1.2,0.64$ \\
$\mathrm{Z}$ & 4 & Multipole refinement \\
$\rho_{\text {calc }}\left(\mathrm{g} / \mathrm{cm}^{3}\right)$ & 2.079 & Reflns. used $[\mathrm{I}>2 \sigma(\mathrm{I})]$ & 7797 \\
$\mathrm{~F}(000)$ & 456 & No. of parameters & 321 \\
$\left.\mu .(\mathrm{mm})^{-1}\right)$ & 5.757 & $\mathrm{R}_{1}(\mathrm{~F})$ & 0.027 \\
$\mathrm{~T}(\mathrm{~K})$ & $100(2)$ & $\mathrm{wR}_{2}(\mathrm{~F})$ & 0.026 \\
$\lambda(\AA)$ & 0.71073 & Goodness-of-fit & 0.992 \\
$(\sin \theta / \lambda)_{\max }\left(\AA^{-1}\right)$ & 1.19 & $\Delta \rho_{\text {min,max }}\left(\mathrm{e} \AA^{-3}\right)$ & $-0.31,0.32$ \\
\hline
\end{tabular}




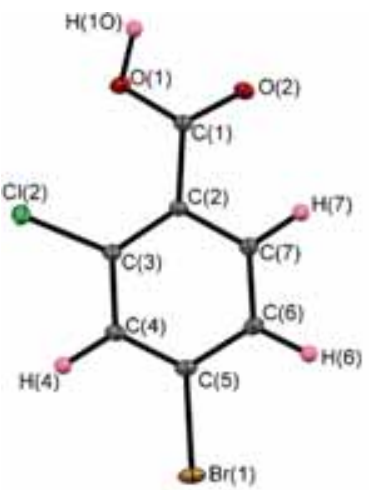

(a)

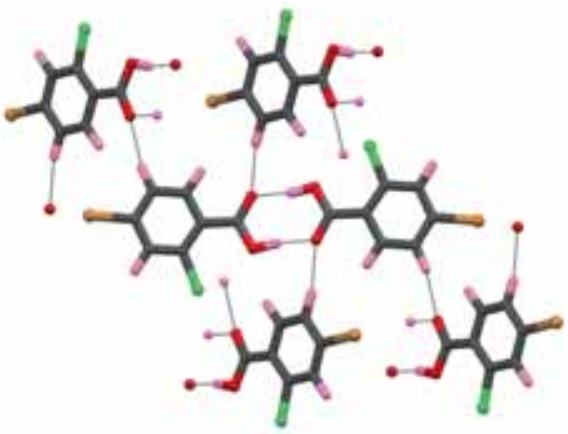

(b)
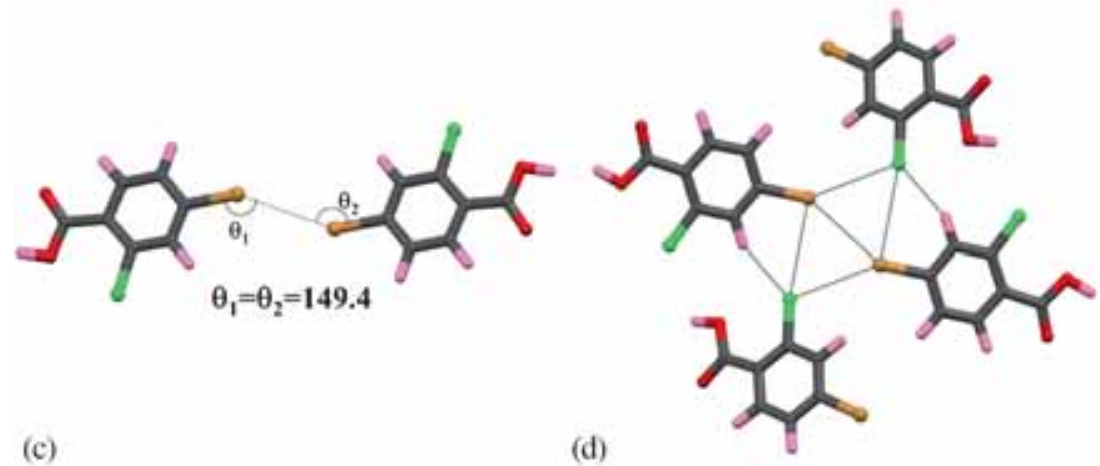

(c)

(d)

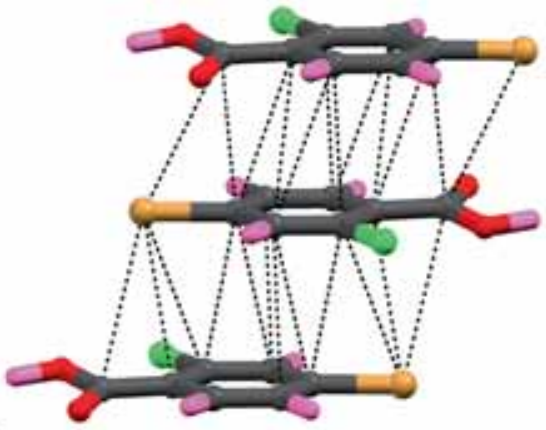

(e)

Figure 1. Molecular structure with the variety of interactions involving bromine in the crystal structure: (a) The ORTEP of the asymmetric unit in BRCL; (b) carboxylic acid dimers and $\mathrm{C}-\mathrm{H} \cdots \mathrm{O}$ infinite chain; (c) $\mathrm{Br} \cdots \mathrm{Br}$ contacts; (d) $\mathrm{C}-\mathrm{H} \cdots \mathrm{Cl}$ and $\mathrm{Br} \cdots \mathrm{Br}$ contacts in $\mathrm{Br}_{2} \mathrm{Cl}$ interaction motif; (e) $\pi \cdots \pi$ and $\mathrm{Br} \cdots \pi$ interactions. The red, orange, black and pink colors represent the oxygen, bromine, carbon and hydrogen atoms.

Table 2. Intermolecular interactions present in BRCL.

\begin{tabular}{lccc}
\hline $\operatorname{At}(\mathbf{I}) \cdots \operatorname{At}(\mathbf{J})$ & $\mathbf{D}(\mathbf{I} \cdots \mathbf{J})$ & $\angle \mathbf{X}-\mathbf{I} \cdots \mathbf{J}\left(^{\circ}\right)$ & Symmetry \\
\hline $\mathrm{O} 1-\mathrm{H} 1 \mathrm{O} \cdots \mathrm{O} 2$ & $2.656(1)$ & 172 & $1-\mathrm{x},-1-\mathrm{y}, 1-\mathrm{z}$ \\
$\mathrm{C} 4-\mathrm{H} 4 \cdots \mathrm{C} 2$ & $3.6837(8)$ & 154 & $3 / 2-\mathrm{x}, 1 / 2+\mathrm{y}, 1 / 2-\mathrm{z}$ \\
$\mathrm{C} 6-\mathrm{H} 6 \cdots \mathrm{O} 2$ & $3.288(1)$ & 167 & $3 / 2-\mathrm{x}, 1 / 2+\mathrm{y}, 3 / 2-\mathrm{z}$ \\
$\mathrm{Br} 1 \cdots \mathrm{Br} 1$ & $3.6715(3)$ & $149.43(2)$ & $2-\mathrm{x}, 1-\mathrm{y}, 1-\mathrm{z}$ \\
$\mathrm{C} 2 \cdots \mathrm{Br} 1$ & $3.6124(6)$ & $115.08(3)$ & $1 / 2+\mathrm{x}, 1 / 2-\mathrm{y}, 1 / 2+\mathrm{z}$ \\
$\mathrm{C} 2 \cdots \mathrm{Br} 1$ & $3.7352(6)$ & $163.39(4)$ & $3 / 2-\mathrm{x},-1 / 2+\mathrm{y}, 1 / 2-\mathrm{z}$ \\
$\pi \cdots \pi$ & $3.5910(4)$ & - & $1-\mathrm{x},-\mathrm{y}, 1-\mathrm{z}$ \\
$\pi \cdots \pi$ & $3.7331(4)$ & - & $2-\mathrm{x},-\mathrm{y}, 1-\mathrm{z}$ \\
\hline
\end{tabular}




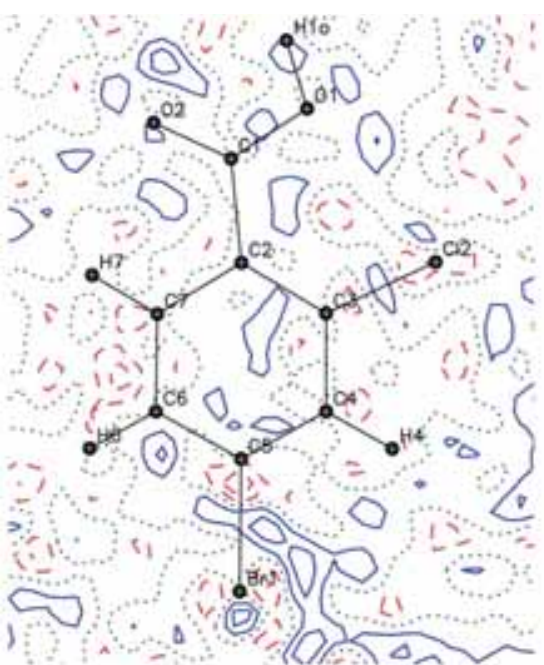

(a)

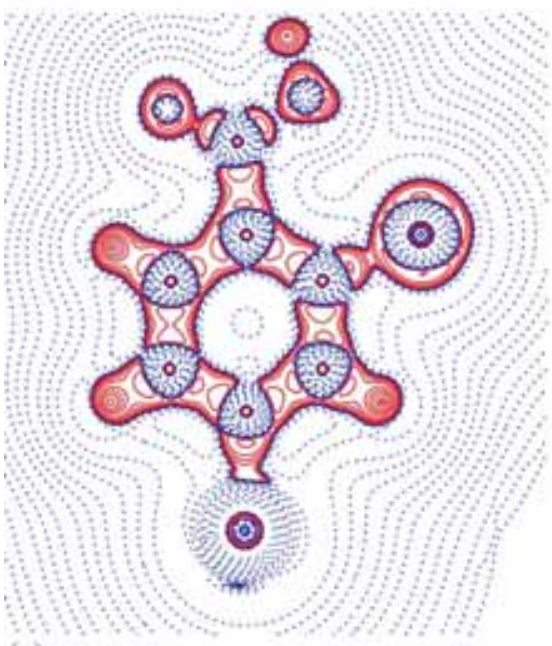

(c)

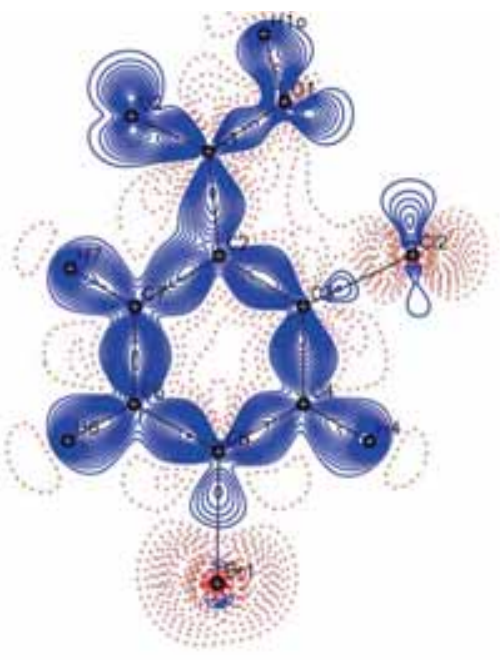

(b)

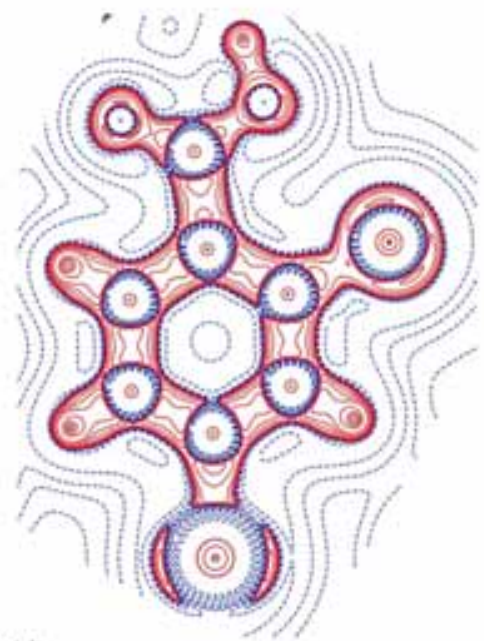

(d)

Figure 2. (a) Residual density; (b) deformation density $\left(\Delta \rho\right.$ (r) $=\rho_{\text {multipole }}-$ $\left.\rho_{\text {spherical }}\right)$; (c) Laplacian maps obtained after multipolar refinement of the experimental charge density data of BRCL; and (d) Laplacian map obtained from theory. Blue (solid lines), red (broken lines) colors represent positive, negative contours respectively (reversed in case of Laplacian). Contours are drawn at the intervals of \pm 0.05 e $\AA^{-3}$. Laplacian is plotted on logarithmic contours.

Table 3. Topological parameters for intermolecular interactions obtained from experimental ( $1^{\text {st }}$ line) and TOPOND calculations ( $2^{\text {rd }}$ line) in BRCL.

\begin{tabular}{|c|c|c|c|c|c|c|c|c|}
\hline & $\mathbf{R}_{\mathrm{ij}}(\AA)$ & $\rho\left(\mathbf{e}^{-3}\right)$ & $\nabla^{2} \rho\left(\mathbf{e}^{-5}\right)$ & $\varepsilon$ & $\mathbf{G}\left(\mathrm{kJ} \mathrm{Mol}^{-1} \mathrm{bohr}^{-3}\right)$ & V (kJ Mol $\mathbf{M o h r}^{-\mathbf{3}}$ ) & $|\mathbf{V}| / \mathbf{G}$ & $\mathrm{E}_{\mathrm{int}}\left(\mathrm{kJ} \mathrm{mol}^{-1}\right)$ \\
\hline \multirow[t]{2}{*}{$\mathrm{Br} 1 \cdots \mathrm{Br} 1$} & 3.6673 & $0.056(1)$ & $0.536(2)$ & 0.02 & 12.3 & -10.0 & 0.81 & -5.0 \\
\hline & & 0.05 & 0.46 & 0.03 & 11.0 & -8.7 & 0.80 & -4.2 \\
\hline \multirow[t]{2}{*}{$\mathrm{Br} 1 \cdots \mathrm{Cl} 2$} & 3.7327 & $0.041(1)$ & $0.403(1)$ & 0.19 & 10.5 & -8.4 & 0.74 & -3.2 \\
\hline & & 0.041 & 0.43 & 0.13 & 8.7 & -6.4 & 0.74 & -3.5 \\
\hline \multirow[t]{2}{*}{$\mathrm{Br} 1 \cdots \mathrm{Cl} 2$} & 3.6133 & $0.051(1)$ & $0.516(2)$ & 0.02 & 9.3 & -6.9 & 0.77 & -4.3 \\
\hline & & 0.05 & 0.48 & 0.01 & 11.3 & -8.7 & 0.79 & -4.3 \\
\hline \multirow[t]{2}{*}{$\mathrm{O} 2 \cdots \mathrm{H} 1$} & 1.6455 & $0.29(7)$ & $5.54(9)$ & 0.03 & 139.8 & -128.7 & 0.92 & -64.3 \\
\hline & & 0.32 & 3.38 & 0.01 & 108.1 & -124.0 & 1.15 & -62.0 \\
\hline \multirow[t]{2}{*}{$\mathrm{Cl} 2 \cdots \mathrm{H} 4$} & 2.6942 & $0.058(2)$ & $0.744(2)$ & 0.02 & 16.2 & -12.2 & 0.75 & -6.1 \\
\hline & & 0.06 & 0.63 & 0.03 & 14.3 & -11.5 & 0.80 & -5.7 \\
\hline \multirow[t]{2}{*}{$\mathrm{Br} 1 \cdots \mathrm{C} 2$} & 3.6099 & $0.051(2)$ & $0.467(1)$ & 0.51 & 10.7 & -8.6 & 0.81 & -4.3 \\
\hline & & 0.05 & 0.48 & 0.70 & 10.8 & -8.6 & 0.79 & -4.3 \\
\hline
\end{tabular}




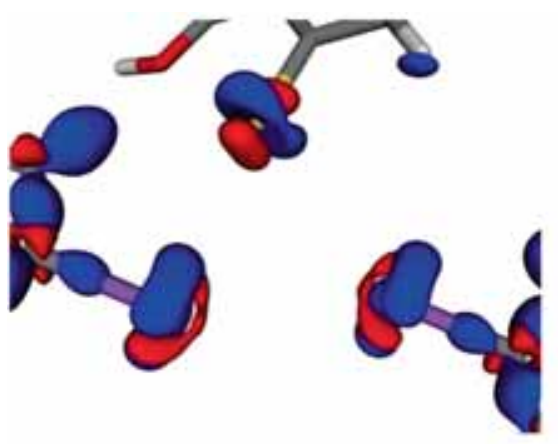

(a)

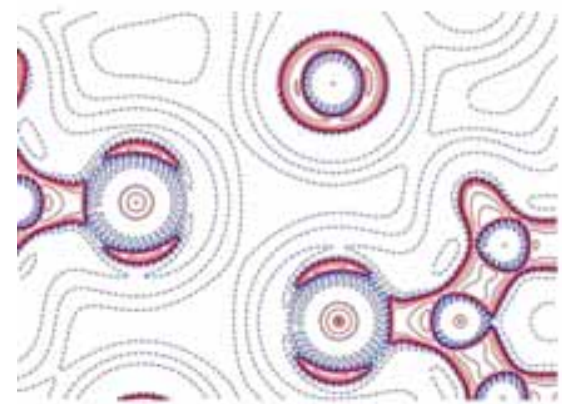

(c)

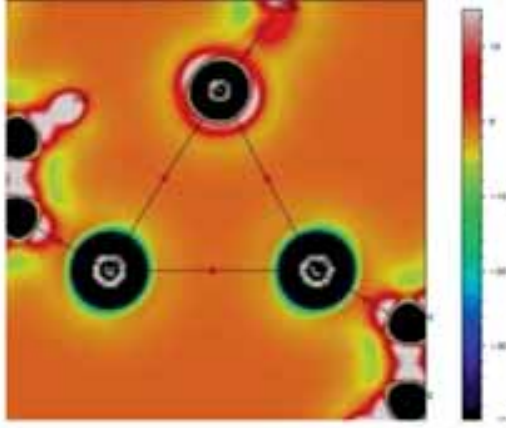

(b)

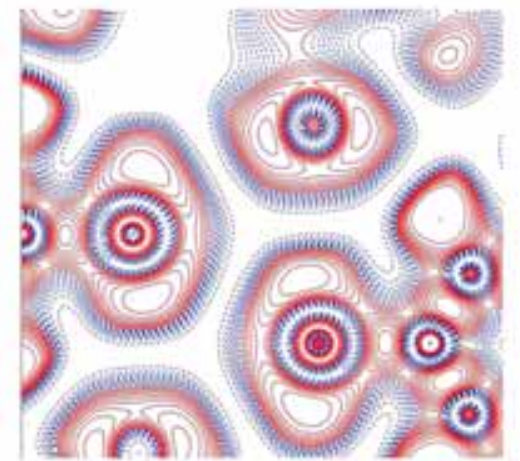

(d)

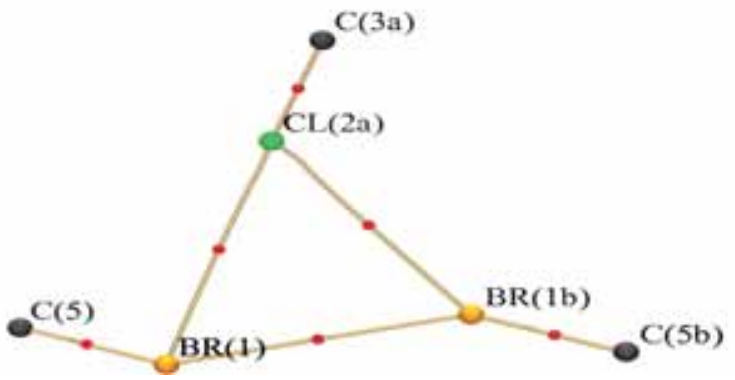

(e)

Figure 3. Topological analysis of the $\mathrm{Br}_{2} \mathrm{Cl}$ interaction region from (a) 3D deformation density (blue represents charge concentration (CC) and red represents charge depletion (CD) contours which are drawn at the intervals of \pm 0.05 $\mathrm{e}^{-3}$ ); (b) 2D Laplacian plots from experiment (colour scale for Laplacian is given in figure); (c) and (d) 2D Laplacian and 2D ELF plot from TOPOND; (e) Molecular graph of $\mathrm{Br}_{2} \mathrm{Cl}$ interaction.

hydrogen bonds and two well defined type II interactions $(\mathrm{Cl} \cdots \mathrm{Br}$ and $\mathrm{Br} \cdots \mathrm{Cl}$ ) (Figure 1d). However, it is noteworthy that these concerted interaction motif results in the stabilization of the repulsive type I $\mathrm{Br} \cdots \mathrm{Br}$ contact. Additionally, the structure is also stabilized by $\pi \cdots \pi$ and $\mathrm{Br} \cdots \pi$ interactions (Figure 1e). Table 2 summarizes the interaction parameters.

\subsection{Multipole refinement}

The topological features of all the intermolecular interactions have been explored based on multipole modeling on both experimental and theoretical structure factors using the Hansen-Coppens formalism. Hirshfeld rigid bond test applied to all the covalent bonds involving non-hydrogen atoms validate the quality of multipole model after the final cycle of refinement. ${ }^{43}$ The $\mathrm{C} 2-\mathrm{C} 3$ single bond has the largest difference of mean-square displacement amplitude (DMSDA) value of $7 \times 10^{-4}$ $\AA^{2}$. The residual electron density peaks are of -0.31 $\mathrm{e}^{-3}$ and $0.32 \mathrm{e}^{-3}$ with an RMS value of 0.08 $\mathrm{e}^{-3}$ for minimum and maximum values respectively. The fractal dimension plot is symmetric in nature and parabolic in shape (see Supplementary Information). The residuals are fairly normal considering the data was collected on a crystal containing bromine. The static 


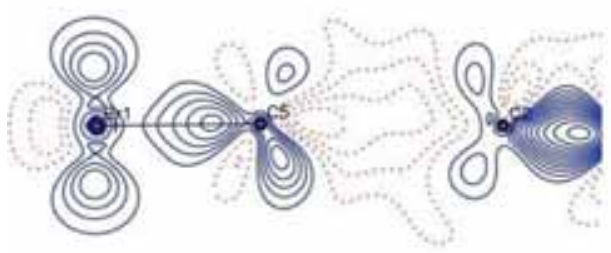

(a)

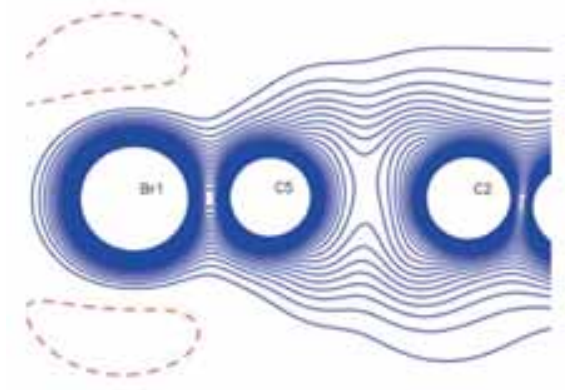

(c)

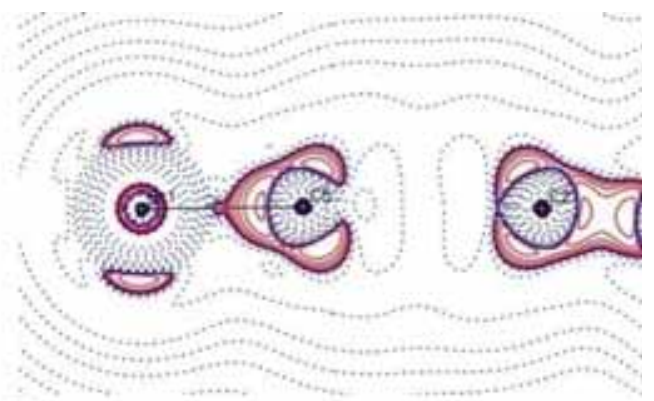

(b)

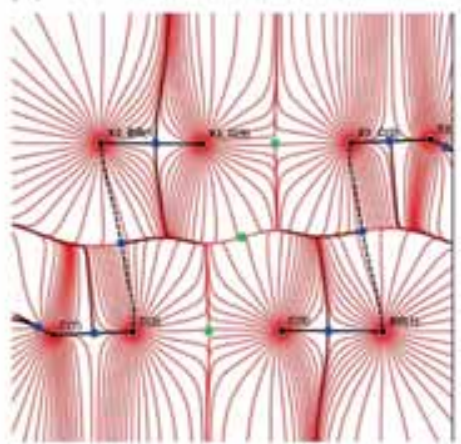

(d)

Figure 4. Topological analysis of the $\mathrm{Br} \cdots \pi$ interaction region (a) 2D deformation; (b) 2D Laplacian; (c) 2D electrostatic potential plots in plane perpendicular to the benzene ring; (d) Gradient trajectory plot of $\mathrm{Br} \cdots \pi$ interaction region.

deformation density and Laplacian maps represent the essential chemical features such as the aspherical nature of the electron density around bromine atom (Figure 2). The Laplacian maps for experiment and theory differ significantly in the molecular plane, but are nearly similar in its perpendicular plane indicating absorption affects observed in other heavy atom experimental charge density datasets. ${ }^{44-46}$

\subsection{Topological analysis}

The topological analysis of both intra- and intermolecular interactions revealed several of $(3,-1)$ bond critical points (BCPs). The values $\mathrm{R}_{\mathrm{ij}}, \mathrm{d}_{1}$ and $\mathrm{d}_{2}, \rho_{\mathrm{cp}}$ (electron density at the critical point), $\nabla^{2} \rho_{\mathrm{cp}}$, ellipticity $(\varepsilon), \mathrm{G}_{\mathrm{cp}}$ and $\mathrm{V}_{\mathrm{cp}}$ obtained from both experimental and theoretical TOPOND calculations are listed in Supplementary Information (SI) and Table 3 and the values are in agreement with each other demonstrating that both methodologies provide consistent measure of the topological properties in the present study.

The topological values for the $\mathrm{O}-\mathrm{H} \cdots \mathrm{O}$ interaction in the carboxylic acid dimers are larger than all the remaining interactions in the crystal structure, proving its strength in holding the crystal structure together. The features of such hydrogen bonds have been discussed in depth by several groups including us in the past. ${ }^{17,47-50}$ The topological values of the three interactions in the $\mathrm{Br}_{2} \mathrm{Cl}$ triangular motif also depict the closed shell nature (because for a close-shell interaction the value of $\nabla^{2} \rho$ at the critical point is $+v e$ ), which is further proved by the modulus of the ratio between kinetic and potential energy densities at the BCP, obtained by utilizing the Abramov expression. ${ }^{51}$ Similar observations have been made in our previous work on halogen interactions. ${ }^{16,17,21,52}$ The $3 \mathrm{D}$ deformation density plots depict the $\delta^{+} \ldots \delta^{-}$nature of the interaction as the charge depletion (CD) along the $\mathrm{C}-\mathrm{Cl}$ bond axis is facing the charge concentration $(\mathrm{CC})$ region on the bromine atoms (Figure 3a). But similar observation is not clear from the 2D Laplacian plot, as CC regions on chlorine is observed, whereas this feature is obscure at the bromine site in the maps generated by experimental multipole modeling (Figure 3b). However, in case of the theoretical plots we clearly observe the polar flattening features on both bromine and chlorine (the polar flattening effect is more in case of bromine)as shown in Figure 3c. To observe the regions of lonepairs in both bromine and chlorine ELF was plotted from the theoretical charge density model using TOPOND (Figure 3d), which clearly shows the charge concentration regions on all halogen atoms which are a part of the triangular interaction motif. ${ }^{53,54}$ The net interaction energy for the triangular interaction motif (Figure $3 \mathrm{e}$ ) calculated using the EML method ${ }^{51,55,56}$ is $-12.5 \mathrm{~kJ} \mathrm{~mol}^{-1}$, indicating the Gulliver effect of weak 
interactions. ${ }^{47}$ If the triangle is extended as shown in Figure 1d, the energy of the corresponding tetramer which is having additional $\mathrm{C}-\mathrm{H} \cdots \mathrm{Cl}$ interactions and two $\mathrm{Cl} \cdots \mathrm{Br}$ contacts, increases to $-32 \mathrm{~kJ} \mathrm{~mol}^{-1}$. This provides the basis for the understanding of the presence of the otherwise repulsive $\mathrm{Br} \cdots \mathrm{Br}$ contact in the structure as the repulsion is extensively reduced by several attractive interactions.

The analysis of the $\mathrm{Br}_{2} \mathrm{Cl}$ interaction confirms its role in the stabilization of type $\mathrm{I} \mathrm{Br} \cdots \mathrm{Br}$ contacts. The stacking interaction between the aromatic moieties further augments the type $\mathrm{I} \mathrm{Br} \cdots \mathrm{Br}$ contacts. The energy calculated between stacking dimers is found to be -7.8 and $-9.8 \mathrm{kcal} \mathrm{mol}^{-1}$. However, it is noteworthy that the lone pair concentrations of the bromine atom are interacting with the adjacent benzene rings (Figure 4a and b) their contribution further adds to the stability of $\pi \cdots \pi$ stacks. The nature of this interaction is clearly observed in the ESP(electrostatic potential) plot (Figure 4c) which shows the $\delta^{-}$regions of bromine interacting with $\delta^{+}$regions of the carbon atom in the benzene ring. Additional confirmation is offered by the gradient trajectory plot (Figure 4d) where a bond path between the bromine atom and the carbon atom in the benzene ring is observed.

\section{Conclusions}

The recognition of the $X_{3}$ synthon reported in literature and its relevance in the context of the current study brings out the salient influence of a concerted interaction motif involving several surrogate contacts contributing to the stability of an otherwise repulsive $\mathrm{Br}$.. Br type I contact. Certainly the motif identified in the current study cannot be classified as an $\mathrm{X}_{3}$ synthon, however features derived from the 3D deformation density analysis clearly suggests that both $\mathrm{Br} \cdots \mathrm{Cl}$ contacts correspond to a $\delta^{+} \cdots \delta^{-}$interaction, reminiscent of a type II contact. The relevance of charge density analysis is thus evidenced as the gold standard in the classification and identification of intermolecular interactions rather than a mere use of geometrical factors.

\section{Supplementary Information (SI)}

The electronic supporting information can be seen at www.ias.ac.in/chemsci.

\section{Acknowledgements}

MSP thanks IISc for research associateship and TNG thanks DST for the J. C. Bose National Fellowship.

\section{References}

1. Arunan E, Desiraju G R, Klein R A, Sadlej J, Scheiner S, Alkorta I, Clary D C, Crabtree R H, Dannenberg J J and Hobza P 2011 Pure Appl. Chem. 831637

2. Jeffrey G A and Saenger W 1994 In Hydrogen Bonding in Biological Structures (Berlin: Springer-Verlag)

3. Desiraju G and Steiner T 1999 In The Weak Hydrogen Bond: In Structural Chemistry and Biology (Oxford: Oxford University Press)

4. Desiraju G R, Ho P S, Kloo L, Legon A C, Marquardt R, Metrangolo P, Politzer P, Resnati G and Rissanen K 2013 Pure Appl. Chem. 851711

5. Metrangolo P and Resnati G 2015 In Halogen Bonding I: Impact on Materials Chemistry and Life Sciences (Switzerland: Springer) Vol. 358

6. Sarma J A R P and Desiraju G R 1986 Acc. Chem. Res. 19222

7. Saraswatula V G and Saha B K 2014 New J. Chem. 38 897

8. Mukherjee A, Tothadi S and Desiraju G R 2014 Acc. Chem. Res. 472514

9. Saraswatula V G and Saha B K 2015 Chem. Commun. 519829

10. Desiraju G R and Parthasarathy R 1989 J. Am. Chem. Soc. 1118725

11. Pedireddi V R, Reddy D S, Goud B S, Craig D C, Rae A D and Desiraju G R 1994 J. Chem. Soc., Perkin Trans. 2 2353

12. Tothadi S, Joseph S and Desiraju G R 2013 Cryst. Growth Des. 133242

13. Saha B K, Rather S A and Saha A 2016 Cryst. Growth Des. 163059

14. Tsirelson V G, Zhou P F, Tang T-H and Bader R F W 1995 Acta Crystallogr., Sect. A: Found. Crystallogr. 51 143

15. Bui T T T, Dahaoui S, Lecomte C, Desiraju G R and Espinosa E 2009 Angew. Chem. Int. Ed. 483838

16. Hathwar V R and Row T N G 2010 J. Phys. Chem. A 11413434

17. Hathwar V R and Row T N G 2011 Cryst. Growth Des. 111338

18. Hathwar V R, Chopra D, Panini P and Row T N G 2014 Cryst. Growth Des. 145366

19. Brezgunova M E, Aubert E, Dahaoui S, Fertey P, Lebegue S, Jelsch C, Angyan J G and Espinosa E 2012 Cryst. Growth Des. 125373

20. Bertolotti F, Shishkina A V, Forni A, Gervasio G, Stash A I and Tsirelson V G 2014 Cryst. Growth Des. 143587

21. Pavan M S, Prasad K D and Row T N G 2013 Chem. Commun. 497558

22. Wang R, Dols T S, Lehmann C W and Englert U 2012 Chem. Commun. $\mathbf{4 8} 6830$

23. Nelyubina Y V, Antipin M Y, Dunin D S, Kotov V Y and Lyssenko K A 2010 Chem. Commun. 465325

24. Reddy C M, Kirchner M T, Gundakaram R C, Padmanabhan K A and Desiraju G R 2006 Chem. Eur. J. 122222

25. Bader R F W 1990 In Atoms in Molecules: A Quantum Theory (Oxford: Oxford University Press)

26. Blessing R 1997 J. Appl. Crystallogr. 30421 
27. Sheldrick G 2008 Acta Crystallogr., Sect. A: Found. Crystallogr. 64112

28. Sheldrick G 2015 Acta Crystallogr., Sect. C: Cryst. Struct. Commun. $\mathbf{7 1} 3$

29. Macrae C F, Edgington P R, McCabe P, Pidcock E, Shields G P, Taylor R, Towler M and van de Streek J 2006 J. Appl. Crystallogr. 39453

30. Coppens P and Hansen N K 1977 Isr. J. Chem. 16163

31. Hansen N K and Coppens P 1978 Acta Crystallogr., Sect. A: Found. Crystallogr. 34909

32. Volkov A, Macchi P, Farrugia L J, Gatti C, Mallinson P R, Richter T and Koritsanszky T S 2006 In XD2006 5.34 (New York: University of Buffalo)

33. Su Z and Coppens P 1997 Acta Crystallogr., Sect. A: Found. Crystallogr. $\mathbf{5 3} 749$

34. Macchi P and Coppens P 2001 Acta Crystallogr., Sect. A: Found. Crystallogr. 57656

35. Becker P J and Coppens P 1974 Acta Crystallogr., Sect. A: Found. Crystallogr. 30129

36. Zhao Y and Truhlar D 2008 Theor. Chem. Acc. 120215

37. Peintinger M F, Oliveira D V and Bredow T $2013 \mathrm{~J}$. Comput. Chem. 34451

38. Dovesi R, Saunders V R, Roetti C, Orlando R, ZicovichWilson C M, Pascale F, Civalleri B, Doll K, Harrison N M, Bush I J, D'Arco P, Llunell M, Causa M and Noel Y 2014 CRYSTAL14 manual

39. Frisch M, Trucks G, Schlegel H, Scuseria G, Robb M, Cheeseman J, Scalmani G, Barone V, Mennucci B and Petersson G 2009 Gaussian 09, Revision D. 01

40. Chai J-D and Head-Gordon M 2008 Phys. Chem. Chem. Phys. 106615

41. Boys S F and Bernardi F D 1970 Mol. Phys. 19553

42. Simon S, Duran M and Dannenberg J 1996 J. Chem. Phys. 10511024
43. Hirshfeld F 1976 Acta Crystallogr., Sect. A: Found. Crystallogr. 32239

44. Schmøkel M S, Bjerg L, Larsen F K, Overgaard J, Cenedese S, Christensen M, Madsen G K H, Gatti C, Nishibori E, Sugimoto K, Takata M and Iversen B B 2013 Acta Crystallogr., Sect. A: Found. Crystallogr. 69 570

45. Kaminski R, Domagala S, Jarzembska K N, Hoser A A, Sanjuan-Szklarz W F, Gutmann M J, Makal A, Malinska M, Bak J M and Wozniak K 2014 Acta Crystallogr., Sect. A: Found. Crystallogr. $\mathbf{7 0} 72$

46. Brezgunova M E, Aubert E, Dahaoui S, Fertey P, Lebegue S, Jelsch C, Angyan J G and Espinosa E 2012 Cryst. Growth Des. 125373

47. Thomas S P, Pavan M S and Guru Row T N 2012 Cryst. Growth Des. 126083

48. Zobel D, Luger P, Dreissig W and Koritsanszky T 1992 Acta Crystallogr., Sect. B: Struct. Sci. 48837

49. Zhurov V V and Pinkerton A A 2014 Cryst. Growth Des. 145685

50. Zhurov V V and Pinkerton A A 2015 J. Phys. Chem. A 11913092

51. Abramov Y A 1997 Acta Crystallogr. Sect. A: Found. Crystallogr. $\mathbf{5 3} 264$

52. Pavan M S, Pal R, Nagarajan K and Guru Row T N 2014 Cryst. Growth Des. 145477

53. Becke A D and Edgecombe K E 1990 J. Chem. Phys. 92 5397

54. Savin A, Nesper R, Wengert S and Fässler T F 1997 Angew. Chem. Int. Ed. 361808

55. Espinosa E, Molins E and Lecomte C 1998 Chem. Phys. Lett. 285170

56. Espinosa E and Molins E 2000 J. Chem. Phys. 113 5686 